\title{
Diversity of tsetse flies and trypanosome species circulating in the area of Lake Iro in southeastern Chad
}

\author{
Djoukzoumka Signaboubo 1,2,3 , Vincent Khan Payne ${ }^{3}$, Ibrahim Mahamat Alhadj Moussa2, \\ Hassane Mahamat Hassane ${ }^{4}$, Petra Berger ${ }^{2}$, Soerge Kelm² and Gustave Simo ${ }^{1 *}$ (i)
}

\begin{abstract}
Background: African trypanosomiases are vector-borne diseases that affect humans and livestock in sub-Saharan Africa. Although data have been collected on tsetse fauna as well as trypanosome infections in tsetse flies and mammals in foci of sleeping sickness in Chad, the situation of tsetse fly-transmitted trypanosomes remains unknown in several tsetse-infested areas of Chad. This study was designed to fill this epidemiological knowledge gap by determining the tsetse fauna as well as the trypanosomes infecting tsetse flies in the area of Lake Iro in southeastern Chad.

Methods: Tsetse flies were trapped along the Salamat River using biconical traps. The proboscis and tsetse body were removed from each fly. DNA was extracted from the proboscis using proteinase $\mathrm{K}$ and phosphate buffer and from the tsetse body using Chelex $5 \%$. Tsetse flies were identified by amplifying and sequencing the cytochrome c oxydase I gene of each tsetse fly. Trypanosome species were detected by amplifying and sequencing the internal transcribed spacer 1 of infecting trypanosomes.

Results: A total of 617 tsetse flies were trapped; the apparent density of flies per trap per day was 2. 6. Of the trapped flies, 359 were randomly selected for the molecular identification and for the detection of infecting trypanosomes. Glossina morsitans submorsitans (96.1\%) was the dominant tsetse fly species followed by G. fuscipes fuscipes (3.1\%) and G. tachinoides (0.8\%). Four trypanosome species, including Trypanosoma vivax, T. simiae, T. godfreyi and T. congolense savannah, were detected. Both single infection (56.7\%) and mixed infections of trypanosomes (4.6\%) were detected in G. m. submorsitans. The single infection included T. simiae (20.5\%), T. congolense savannah (16.43\%), T. vivax (11.7\%) and T. godfreyi (9.8\%). The trypanosome infection rate was $61.4 \%$ in G. $m$. submorsitans, $72.7 \%$ in G. f. fuscipes and $66.6 \%$ in G. tachinoides. Trypanosome infections were more prevalent in tsetse bodies (40.6\%) than in the proboscis (16.3\%).
\end{abstract}

Keywords: Trypanosome infections, Tsetse fly, AAT, Lake Iro, Chad

\section{Background}

African trypanosomiases are parasitic diseases that are widely spread throughout sub-Saharan Africa. They are caused by African trypanosomes and induce morbidity

\footnotetext{
*Correspondence: gsimoca@yahoo.fr; gustave.simo@univ-dschang.org

${ }^{1}$ Molecular Parasitology and Applied Entomology Unit, Department

of Biochemistry, Faculty of Science, University of Dschang, PO Box 67, Dschang, Cameroon

Full list of author information is available at the end of the article
}

and mortality both in humans and animals. Human African trypanosomiasis (HAT), or sleeping sickness, is a neglected tropical disease (NTD) caused by two trypanosome subspecies: Trypanosoma brucei gambiense, which is responsible for the chronic form of the disease in western and central African regions, and T. b. rhodesiense, which induces the acute form of the disease in southern and eastern African regions [1].

Animal African trypanosomiasis (AAT), or nagana, is caused by several trypanosome species or subspecies, 
including T. vivax, T. simiae, T. $b$. brucei and T. congolense. Amongst these animal trypanosomes, $T$. congolense is considered to be the most important pathogen due to its economic impact on animal production [2]. In about 38 sub-Saharan African countries with a high potential of producing meat, milk and food crops, AAT is recognized as an important constraint to agriculture, livestock production, food security and animal health. Globally, about 55 million heads of cattle, 30 million sheep and 40 million goats are at risk of trypanosome infections [3]. These infections reduce milk production by $10-40 \%$, the number of cattle by $10-50 \%$ and agricultural production by up to $2-10 \%$. Moreover, direct and indirect losses resulting from the impact of AAT on the African economy have been estimated to be 5 billion euro annually [4]. Controlling AAT will enable the agricultural industry to benefit by about US $\$ 1300$ million per annum [5]. The Pan African Tsetse and Trypanosomiases Eradication Campaign (PATTEC) was launched about 20 years ago with the aim to overcome the economic losses deriving from trypanosome infections in livestock [6]. Achieving the PATTEC goal requires updating knowledge on tsetse distribution and trypanosome infections in both tsetse flies and mammals in different ecological settings. Knowledge of these factors is a pre-requirement for designing and implementing effective control operations against AAT since it could help to identify and map zones presenting high transmission risks where control operations must be deployed [7].

In tsetse-infested areas, transmission of trypanosomes relies mainly on tsetse flies, which are cyclic vectors of African trypanosomes. Given the role played by tsetse flies (Glossina spp.) in the life-cycle of African trypanosomes, it is obvious that data on trypanosome infections in tsetse flies could contribute to an understanding of the transmission of these parasites. In this context, considerable data have been generated on both tsetse fauna and trypanosome infections in tsetse and mammals in foci of sleeping sickness and in most tsetse-infested areas that are subjected to intensive animal breeding [8-10]. However, updating data on tsetse fauna and trypanosome species infecting tsetse and mammals remains important for understanding the current epidemiological situation of tsetse transmitted-trypanosomes in some tsetse-infested areas, such as the National Parks, the lakes and their surrounding areas. Although most of these areas provide bioclimatic conditions favourable for tsetse development and trypanosome transmission, the tsetse fauna as well as the trypanosome infections in tsetse, livestock and wild animals remain not well understood. Identifying the Glossina fauna as well as trypanosome infections in tsetse and mammals appears fundamental for the understanding of the epidemiology of AAT in different ecological settings and for the achievement of the PATTEC goal of eliminating tsetse-transmitted trypanosomes in Africa.

The southern part of Chad is part of the tsetse-infested area of the Soudano-Sahelian region. Although livestock breeding can be considered to be one of the most important economic activities, with more than 93.8 million heads of cattle, sheep, goats, camels, donkey, horses and pigs being bred by inhabitants of tsetse-infested areas [11], few investigations have been carried out on parasitic diseases, such as AAT, that affect livestock health and animal production. Entomological investigations in sleeping sickness foci and some tsetse-infested areas in the same trapping sites have reported the presence of the tsetse fly species Glossina tachinoides, G. fuscipes fuscipes and G. morsitans submorsitans [12, 13]. Although a variety of tsetse species with trypanosome infections have been reported in sleeping sickness foci and in some tsetse-infested areas of Chad, the distribution of infecting trypanosome species or subspecies is still not well understood. Filling knowledge gaps on tsetse-transmitted trypanosomes requires investigations aimed at updating data on Glossina fauna as well as trypanosome infections in various tsetse-infested areas, such as the Lake Iro region that receives, yearly during the dry season, many transhumant herders and nomads searching for grazing and water for their livestock. Although this area provides suitable habitats for tsetse development and trypanosome transmission, the identity of tsetse fauna and trypanosomes circulating in the area of Lake Iro remain largely unknown.

This study was designed to generate entomological and parasitological data on tsetse fauna and trypanosome infections in tsetse flies caught in tsetse infested areas of Lake Iro in the south of Chad.

\section{Methods}

\section{Study area}

The Lake Iro area $\left(09^{\circ} 59^{\prime} 29.1^{\prime \prime} \mathrm{N}, 019^{\circ} 26^{\prime} 55.7^{\prime \prime} \mathrm{E}\right)$ is located $110 \mathrm{~km}$ north of Sarh, the capital city of the Moyen Chari Region in southern Chad. It is located in the catchment area $\left(195,000 \mathrm{~km}^{2}\right)$ of Bahr Salamat, a seasonally intermittent river, that belongs to the Chari-Logone sub-basin originating from the Darfur Region of Sudan. Lake Iro is close to Zakouma National Park (Fig. 1) . During the dry season, wild animals (antelopes, wild boards, monkeys, warthogs, buffaloes) from Zakouma National Park move in and around the lake Iro area to search for water and grazing area. The hydrographic network of the area is dominated by Lake Iro (surface area about $105 \mathrm{~km}^{2}$ ) and the Bahr Salamate River with its tributaries. The area is characterized by dense shrub forests and floodplains. The maximum annual rainfall is between 800 and $1200 \mathrm{~mm}$ [14], the mean annual temperature is $27^{\circ} \mathrm{C}$ and the mean 


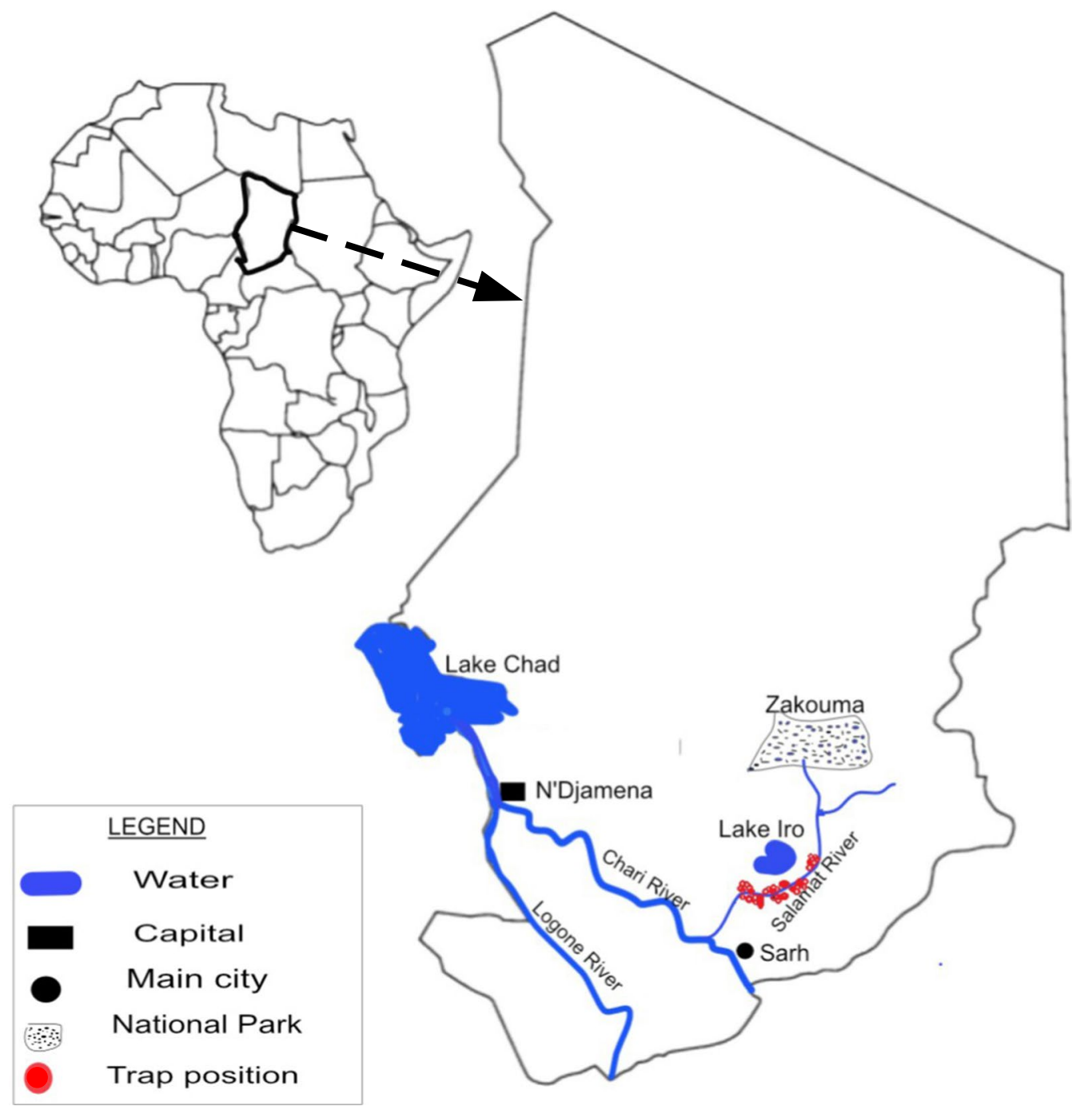

Fig. 1 Localization of the area of lake Iro showing the trapping sites

annual relative humidity is $50 \%$ [15]. The population is estimated at 174,195 inhabitants [16] who practice traditional livestock farming based on pastoralism and agriculture dominated by cereal production.

\section{Entomological survey}

Three entomological surveys were carried out in November 2018, February 2019 and February 2020. During the first survey, 14 biconical traps [17] were set up for 2 days in biotopes favourable to the tsetse fly along the Salamat River and its tributaries. During the second two surveys, 20 traps were set up for 4 consecutive days. The distance between two traps ranged from 100 to $200 \mathrm{~m}$ depending on the density of vegetation. For each trap, geographical coordinates were collected using the global positioning system (model GPSMAP ${ }^{\circledR}$ 60CSx; Garmin
Ltd., Schaffhausen, Switzerland). At each trapping site, temperature and relative humidity were recorded using a thermohygrometer (EasyLog TH; Lascar, Whiteparish, UK). Flies were collected every $24 \mathrm{~h}$ at 9 p.m. During this process, cages containing tsetse flies were collected and transported to the main camp where flies of each trap were counted and morphologically identified to determine the sex and species.

\section{Collection of tsetse fly organs}

From each tsetse fly, the two wings were removed and placed separately in a $1.5-\mathrm{ml}$ dried cryotube for morphometric analyses. The legs, the proboscis and the remaining body (thorax and abdomen) of each tsetse fly were separately put in different $1.5-\mathrm{ml}$ microtubes each containing $200 \mu \mathrm{l}$ nucleic acid preservative solution $(25 \mathrm{mM}$ 
sodium citrate, $10 \mathrm{mM}$ EDTA and $70 \%$ ammonium sulphate). The legs were used for study of the genetic structure of tsetse populations. For each trap that caught < 10 tsetse flies, tsetse organs were collected from all live flies. However, for traps that caught $\geq 10$ tsetse flies, the collected flies were subdivided into two groups; tsetse organs were collected in all live flies of one group and the process repeated until no live tsetse fly could be found in the last group. To avoid cross-contamination of organs from two different tsetse flies, dissecting tweezers were decontaminated by incubation in 5\% sodium hypochlorite solution for $20 \mathrm{~min}$, followed by a washing step in double-distilled water. The collected organs were stored at $4{ }^{\circ} \mathrm{C}$ in the field and conserved at conserved at $-80^{\circ} \mathrm{C}$ in the laboratory.

\section{DNA extraction from the tsetse body}

From each tsetse body, DNA was extracted using 5\% Chelex-resin (Chelex 100; Bio-Rad, Hercules, CA, USA). Briefly, each tsetse body was removed from the nucleic acid preservative solution and put into a new $1.5-\mathrm{ml}$ microtube. The tsetse body was then crushed with the tip of a capped Pasteur pipette and $100 \mu \mathrm{l}$ of homogenized Chelex 5\% solution was added. After incubation of the microtubes in the thermomixer for $30 \mathrm{~min}$ at $56{ }^{\circ} \mathrm{C}$, each microtube was briefly vortexed before another incubation at $95^{\circ} \mathrm{C}$ for $5 \mathrm{~min}$. Each microtube was then centrifuged at 10,000 rpm for $1 \mathrm{~min}$. The supernatant or DNA extract was transferred into another microtube and its concentration determined using the NanoDrop 1000 UV-Vis spectrophotometer (Thermo Fisher Scientific, Waltham, MA, USA). DNA extracts were stored at $-20^{\circ} \mathrm{C}$ for further analyses.

\section{DNA extraction from proboscis}

Each proboscis was removed from the microtube containing the nucleic acid preserving solution and put into a new $1.5-\mathrm{ml}$ microtube containing $55 \mu \mathrm{l}$ of DNA extraction solution (mixture of $9.9 \mu \mathrm{l}$ of proteinase $\mathrm{K}$ at $20 \mathrm{mg} / \mathrm{m}$; with $45.1 \mu \mathrm{L}$ of phosphate buffered saline). Each microtube was centrifuged at 13,400 rpm for $1 \mathrm{~min}$ before its first incubation at $54{ }^{\circ} \mathrm{C}$ for $1 \mathrm{~min}$, followed by a second incubation at $95{ }^{\circ} \mathrm{C}$ for $5 \mathrm{~min}$. Thereafter, each microtube was vortexed and centrifuged at 10,000 rpm for $1 \mathrm{~min}$. DNA extracts were collected and their concentration determined using the NanoDrop 1000 UVVis spectrophotometer (Thermo Fisher Scientific). DNA extracts were stored at $-20^{\circ} \mathrm{C}$ for further analyses.

\section{Molecular identification of tsetse flies}

The morphological identification of each caught tsetse fly was confirmed by amplifying and sequencing the mitochondrial DNA fragment of the cytochrome $c$ oxidase
1 (COI) gene as previously described by Dyer et al. [18] This amplification was done using CO1-sense (5'-TTG ATT TTT TGG TCA TCC AGA AGT-3') and CO1non-sense (5'-TGA AGC TTA AAT TCA TTG CAC TAA TC-3') primers designed by Dyer et al. [18] and performed in a final volume of $25 \mu \mathrm{l}$ containing $2.5 \mathrm{U}$ of DreamTaq polymerase, $2.5 \mu \mathrm{l}$ of DreamTaq buffer $(10 \times)$, $0.2 \mathrm{mM}$ of dNTPs (all provided by Thermo Fisher Scientific), $2 \mu \mathrm{M}$ of each primer and $1 \mu \mathrm{l}$ of DNA extract from the proboscis. The amplification programme consisted of an initial denaturation step of $95^{\circ} \mathrm{C}, 5 \mathrm{~min}$; then denaturation at $94{ }^{\circ} \mathrm{C} / 1 \mathrm{~min}$, annealing at $55{ }^{\circ} \mathrm{C} / 1 \mathrm{~min}$ and elongation at $72{ }^{\circ} \mathrm{C} / 1 \mathrm{~min}$ for 35 cycles; and a final elongation at $72{ }^{\circ} \mathrm{C}$ for $5 \mathrm{~min}$.

At the end of each PCR reaction, $20 \mu \mathrm{l}$ of PCR products was checked by electrophoresis in a 1.5\% agarose gel containing $3 \mu \mathrm{l}$ G-stain (Serva, Heidelberg, Germany). After completion of the electrophoresis, the agarose gel was stained and the produced visualized under UV light and then photographed. The expected size of the COI amplicons was $930 \mathrm{bp}$.

Each sample for which a 930-bp DNA fragment was revealed by electrophoresis was selected and the remaining amplicons purified using the GeneJet DNA Purification Kit (Thermo Fisher Scientific) following the manufacturer's instructions. Each purified COI DNA fragment was sequenced by a commercial company (SeqLab, Göttingen, Germany). The sequences obtained were subjected to BLAST search in the National Center for Biotechnology Information (NCBI) database (Genbank) to identify tsetse species.

\section{Molecular identification of trypanosome species}

Different trypanosome species and subspecies were identified from the proboscis and body of each tsetse fly by amplifying the internal transcribed spacer 1 (ITS1) fragment of the rDNA of trypanosomes as described by Adams et al. [19]. After this amplification, specific identification of each trypanosome species or subspecies was performed by sequencing the amplified ITS1 DNA fragment and comparing the obtained sequences with those available in the gene bank.

\section{Amplifications of ITS1 DNA fragment of trypanosomes}

The amplification of the ITS1 DNA fragment was performed using a nested PCR as described by Adams et al. [19]. In the first PCR, the outer generic primers ITS1Out-sense ( $5^{\prime}$-TGC AAT TAT TGG TCG CGC- $3^{\prime}$ ) and ITS1-Out-non-sense (5'-CTT TGC TGC GTT CTT-3') were used, and the amplification reactions were performed in a final volume of $25 \mu \mathrm{l}$ containing $2.5 \mathrm{U}$ of DreamTaq polymerase $(5 \mathrm{U} / \mu \mathrm{l}), 2,5 \mu \mathrm{l}$ DreamTaq green buffer $(10 \times), 0.2 \mathrm{mM}$ of dNTPs (Thermo Scientific 
Scientific), $2 \mu \mathrm{M}$ of each outer primer and $1 \mu \mathrm{l}$ of DNA extract from the tsetse fly body or $5 \mu \mathrm{l}$ of DNA extract from the proboscis. The amplification programme for the first PCR consisted of one cycle of initial denaturation at $95{ }^{\circ} \mathrm{C}$ for $5 \mathrm{~min}$; then denaturation at $94{ }^{\circ} \mathrm{C} / 1 \mathrm{~min}$, annealing at $54{ }^{\circ} \mathrm{C} / 30 \mathrm{~s}$ and elongation at $72{ }^{\circ} \mathrm{C} / 30 \mathrm{~s}$ for 30 cycles; and a final elongation at $72{ }^{\circ} \mathrm{C}$ for $5 \mathrm{~min}$.

PCR products of the first PCR were diluted (1:1000 dilution), and $1 \mu \mathrm{l}$ was used as the DNA template for the nested PCR. For this PCR, $2 \mu \mathrm{M}$ of each inner primer (ITS1-In-sense: 5' ${ }^{\prime}$ TAG AGG AAG CAA AAG-3'; ITS1In-non-sense: 5'-AAG CCA AGT CAT CCA TCG-3') was used; the amplification reactions were carried out using the same conditions described above for the first PCR.

Amplified products of the second PCR were checked by electrophoresis in 1.5\% agarose gel as described above. Trypanosome species were identified on the basis of length polymorphism of the ITS1 fragments. Trypanosoma congolense strains ( $T$. congolense forest and savannah) are expected to generate DNA fragments of about $650 \mathrm{bp}$ while the expected sizes for T. brucei (s.l.) and T. vivax are around 400 and $150 \mathrm{bp}$, respectively.

\section{Sequencing of amplified DNA fragments of the ITS1 of different trypanosomes}

To confirm the results generated on the basis of length polymorphism of the ITS1 fragment, five representative amplicons for each size were purified using the GenJet Purification Kit (Thermo Fisher Scientific) following the instructions of the manufacturer. All amplicons with a size of $\geq 400$ bp were sequenced directly by a commercial company (SeqLab) while those $<400$ bp were cloned before sequencing.

\section{Cloning and sequencing of amplified ITS1 fragments}

Purified PCR products were cloned into the linearized pJET 1.2/blunt vector using the CloneJET PCR procedure (Thermo Fisher Scientific) according to the manufacturer's instructions. Recombinant colonies were identified by PCR in which a small portion of the colony was scraped with a sterile pipette tip and each scraped colony used as DNA template for a PCR reaction in which the
ITS1 fragment was amplified using the primers described above. Each recombinant colony was picked up and cultured overnight at $37{ }^{\circ} \mathrm{C}$ in $\mathrm{LB}$ medium supplemented with ampicillin $(100 \mu \mathrm{g} / \mathrm{ml})$. The bacterial culture was centrifuged at $4500 \mathrm{~g}$ for $15 \mathrm{~min}$ at $4{ }^{\circ} \mathrm{C}$, following which the pellet was collected and the plasmid DNA purified using the GeneJET Plasmid MiniPrep Kit (Thermo Fischer Scientific) according to instructions of the manufacturer. Plasmid DNA containing DNA fragments of ITS1 was sent to a commercial company (SeqLab) for sequencing.

Geneious Pro version 5. 5. 9 software was used to store, organize and analyse the obtained sequences. Trypanosome species or subspecies was identified by subjecting each ITS1 sequence to BLAST search in the NCBI database (Genbank).

\section{Data analysis}

Statistical analyses were performed using R software [20]. The chi-squared $\left(\chi^{2}\right)$ test was used to compare the infection rates of different trypanosomes. Comparisons were made between infections in the tsetse body and those in the proboscis as well as between infections according to the sex of tsetse flies. Differences were considered to be significant at $P$-values $<0.05$.

\section{Results}

A total of 617 tsetse flies were trapped during the three surveys: 12 in November 2018, 323 in February 2019 and 282 February 2020 (Table 1). The overall apparent density of tsetse flies per trap per day (ADT) was 2.9, with ADT $=0.4$ in November 2018, 4.0 in February 2019 and 3.5 in February 2020 (Table 1). From these tsetse flies, 32 (5.2\%) were tenerals (tsetse flies that have not yet taken a blood meal and consequently have not been exposed to trypanosome infections). We selected 359 non-teneral flies and removed their proboscis, legs and wings as described in section Collection of tsetse fly organs. The remaining body and the proboscis of each tsetse fly were subjected to molecular identification of different trypanosomes. Sex distribution showed that $68.6 \%$ of all flies captured

Table 1 Entomological data according to sampling periods

\begin{tabular}{|c|c|c|c|c|c|c|c|c|}
\hline Sampling period & $\begin{array}{l}\text { Number of } \\
\text { captured tsetse }\end{array}$ & $\begin{array}{l}\text { Number of } \\
\text { teneral flies (\%) }\end{array}$ & $\begin{array}{l}\text { Number of tsetse } \\
\text { selected (\%) }\end{array}$ & $\begin{array}{l}\text { Number of } \\
\text { traps }\end{array}$ & ADT & Number of males (\%) & $\begin{array}{l}\text { Number of } \\
\text { females (\%) }\end{array}$ & Sex ratio \\
\hline December 2018 & 12 & $0(0)$ & $12(100)$ & 14 & 0.4 & $7(58.3)$ & $5(41.7)$ & 1.4 \\
\hline February 2019 & 323 & $18(5.6)$ & $222(68.7)$ & 20 & 4.0 & $231(71.5)$ & $92(28.5)$ & 2.5 \\
\hline February 2020 & 282 & $14(4.9)$ & $125(44.3)$ & 20 & 3.5 & $185(65.6)$ & $97(34.4)$ & 1.9 \\
\hline Total & 617 & $32(5.2)$ & $359(58.2)$ & 54 & 2.6 & $423(68.6)$ & $194(31.4)$ & 2.2 \\
\hline
\end{tabular}

ADT Apparent density of tsetse flies per trap per day 
were males while $31.4 \%$ were females, giving a sex ratio of 2.2 .

\section{Diversity of tsetse flies}

Molecular identification of tsetse flies was carried out on the 359 tsetse flies from which the proboscis, legs, wings and tsetse bodies were collected. From the proboscis of each of these 359 tsetse flies, a COI DNA fragment of around 930 bp was successfully amplified and sequenced. The comparison of sequences generated from different tsetse flies revealed three tsetse species in the area of Lake Iro. Glossina m. submorsitans was the dominant tsetse species and constituted $96.1 \%$ of the 359 tsetse flies that were sequenced; Glossina f. fuscipes represented $3.06 \%$ and G. tachinoides represented only $0.8 \%$ (Table 2 ). Of the 345 tetse flies identified as G. m. submorsitans, 240 were male $(69.5 \%)$ and 105 were female (30.4\%). For the 11 G. f. fuscipes identified, seven (63.6\%) were male and four (36.3\%) were female. All three G. tachinoides identified were female.

\section{Diversity of trypanosome species}

Results of length polymorphism analysis (Fig. 2) and sequencing of ITS1 fragments revealed the presence $T$. congolense savanah, T. vivax, T. simiae and T. godfreyi in tsetse flies caught in the area of Lake Iro. From the randomly selected 359 tsetse flies that were subjected to molecular identification of trypanosomes in the proboscis and the tsetse body, $222(61.8 \%)$ were found with at least one trypanosome infection. Of the 345 G. m. submorsitans analyzed, $212(61.4 \%)$ were infected, of which 196 (56.7\%) and 16 (4.7\%) were found with single and mixed infections of trypanosomes, respectively (Table 2). For the 196 (56.7\%) G. m. submorsitans that carried trypanosomes species in their body or their proboscis, the parasites identified included T. simiae (19.7\%), followed by $T$. congolense savannah (15.9\%), T. vivax (11.3\%) and $T$. godfreyi (9.8\%).

Eight (72.7\%) G. f. fuscipes and two (66.6\%) G. tachinoides were found with trypanosome infections in the proboscis and/or the tsetse body. In G. f. fuscipes, T. congolense savannah (27.3\%) was the most prevalent

Table 2 Type and number (prevalence) of trypanosome infections according to tsetse species

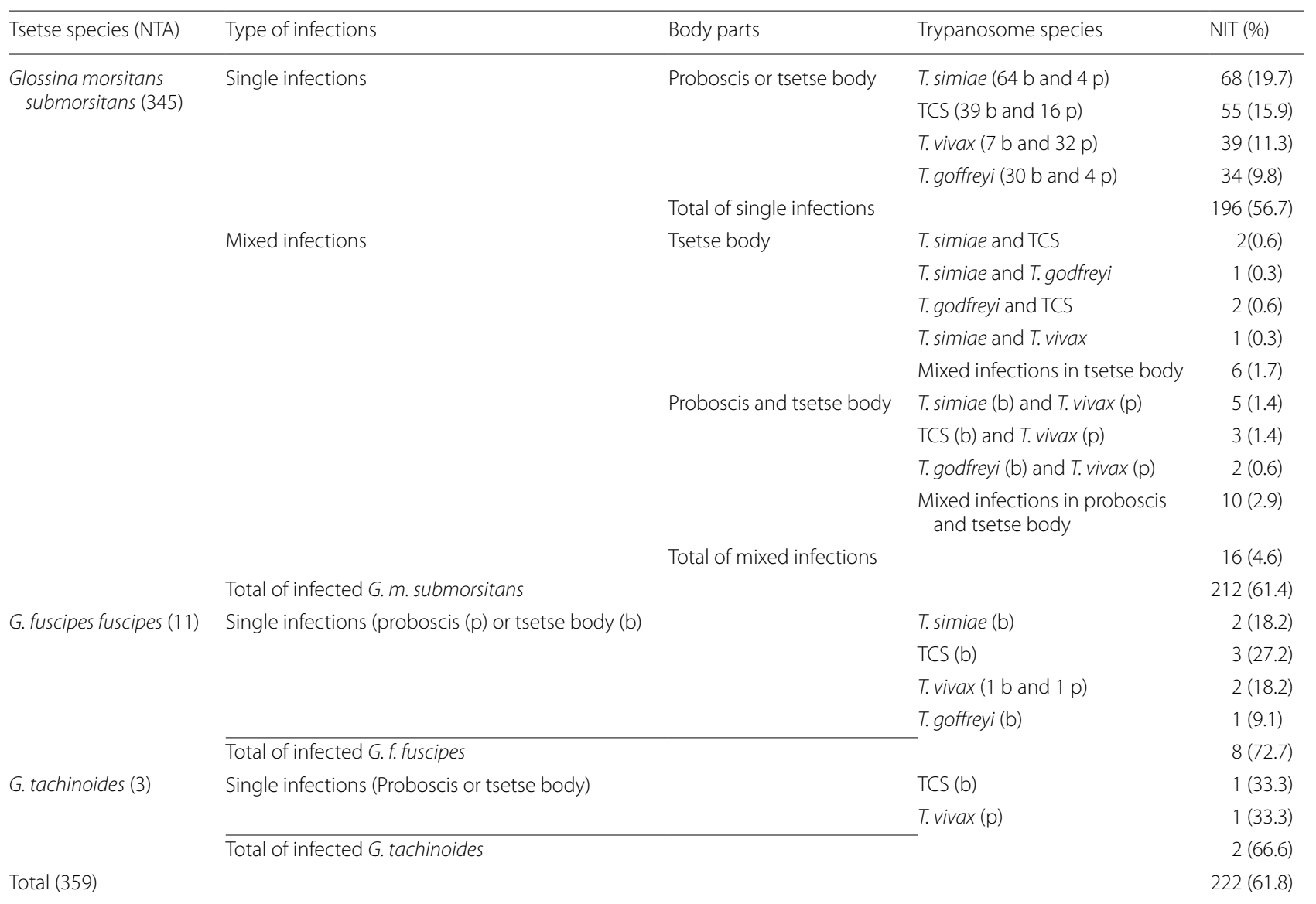

NIT Number of infected tsetse flies, NTA Number of tsetse flies analysed, TCS Trypanosoma congolense savannah, $p$ proboscis, $b$ tsetse body 


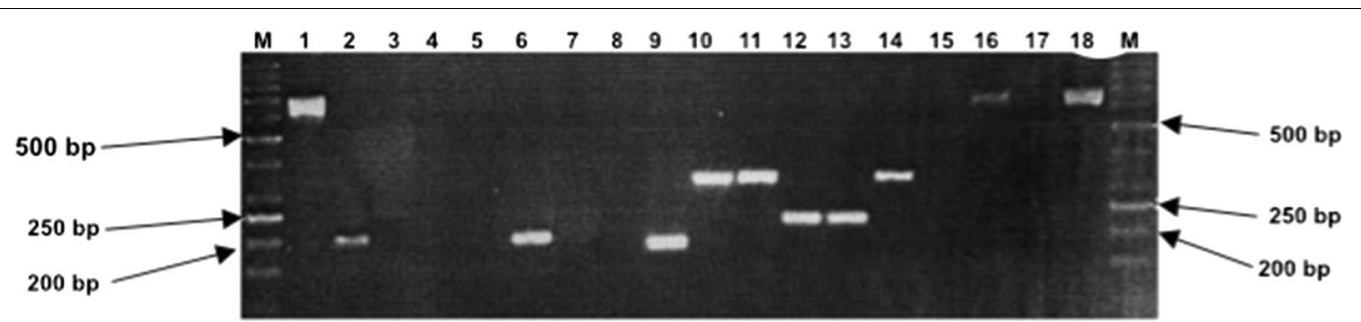

Fig. 2 Example of agarose gel illustrating the electrophoretic profiles generated from the amplification of the internal transcribed spacer 1 fragment of different trypanosome species. Lanes: M Marker GeneRuler 50 bp Ladder (Thermo Fisher Scientific), 1, 16 Trypanosoma congolense, 2, 6, 9 T. vivax, 10, 11, 14 T. simiae, 12, 13 T. godfrey, 17 negative control without DNA template, 18 positive control (genomic T. congolense DNA from infected cattle)

trypanosome species, followed by $T$. simiae (18.2\%), $T$. vivax (18.2\%) and T godfreyi (9.1\%). In G. tachinoides, $T$. congolense savanah and T. vivax were detected in the proboscis and the tsetse body with an identical infection rate of $33.3 \%$ (Table 2 ).

Male and female G. $m$ submorsitans were found with all trypanosome species identified in this study. Comparison of the trypanosome infections revealed that there was no significant difference between males and females for infection with $T$. congolense savanah $\left(\chi^{2}=0.7665\right.$; $P=0.38), T$. vivax $\left(\chi^{2}=0.1035 ; P=0.75\right), T$. godfreyi $\left(\chi^{2}=0.1035 ; P=0.75\right), T$. simiae $\left(\chi^{2}=1.6028 ; P=0.21\right)$ and all trypanosome species taken together $\left(\chi^{2}=0.0067\right.$; $P=0.9$ ). Given the small number of $G$. $f$. fuscipes (11 individuals) and G. tachinoides (3 individuals), no comparison of trypanosome infection rates between sex and tsetse species was performed.

\section{Trypanosome infections in the proboscis and tsetse body}

All trypanosome species identified in this study were found in both the proboscis and the body of G. m. submorsitans. Trypanosome infections were detected in $56(16.2 \%)$ proboscises and $140(40.6 \%)$ bodies of 345 G. $m$. submorsitans. In proboscises, T. vivax was the most prevalent trypanosome species (9.3\%), followed by $T$. congolense savanah (4.6\%) and then $T$. simiae and T. godfreyi with an infection rate of $1.2 \%$ each. In the tsetse body, $T$. simiae was the most prevalent trypanosome species $(18.5 \%)$, followed by $T$. congolense savanah (11.3\%), T. gofreyi (8.7\%) and T. vivax (2.0\%). Comparison of the trypanosome infection rates in G. m. submorsitans revealed a significant difference $\left(\chi^{2}=50.283 ; P<\right.$ $0.00001)$ between infections in the probosis and those of the body. The infection rate of $T$. vivax was significantly higher $\left(\chi^{2}=16.986 ; P<0.00001\right)$ in the proboscis than in the body of G. m. submorsitans.

In G. f. fuscipes, all trypanosome species were detected in tsetse bodies while only $T$. vivax was identifed in the proboscis. Of the 11 G. f. fuscipes studied, only one (9.1\%) infection of $T$. vivax was found in the proboscis while seven $(63.6 \%)$ tsetse bodies were infected by the four species of trypanosomes. Trypanosoma congolense savanah (27.3\%) was the most prevalent trypanosome species, followed by $T$. simiae (18.2\%), then T. vivax and T. godfreyi (both an infection rate of 9.1\%). For G. tachinoides, only T. congolense savanah was detected in the tsetse body and T. vivax in proboscis.

\section{Mixed infections of different trypanosomes}

No mixed infection was detected in the proboscis of all tsetse species analysed nor in the body of G. f. fuscipes and G. tachinoides. Only double infections were detected, and they included six (1.7\%) mixed infections, appearing in the tsetse body only, and ten (2.9\%) others in both the proboscis and tsetse body. The six mixed infections that were detected only in the tsetse body included two (0.6\%) tsetse flies with $T$. simiae and $T$. congolense savanah, two (0.6\%) with $T$. simiae and $T$. godfreyi, one (0.3) with $T$. godfreyi and $T$. congolense savanah, and one $(0.3 \%)$ with T. simiae and T. vivax. For the ten tsetse flies with trypanosome infections in both the proboscis and tsetse body, five $(1.4 \%)$ had $T$. simiae in the tsetse body and T. vivax in the proboscis; three $(0.9 \%)$ had $T$. congolense savannah in the tsetse body and T. vivax in the proboscis and two $(0.6 \%)$ had $T$. godfreyi and T. vivax respectively in the tsetse body and the proboscis (Table 2).

\section{Discussion}

Although several investigations have been undertaken in sleeping sickness foci of Chad to generate data on tsetse fauna as well as trypanosome infections in human and animals $[12,13,21,22]$, the situation of tsetse-transmitted trypanosomiases remains unknown in several tsetseinfested areas. This study was designed to fill this gap by identifying tsetse species and trypanosomes infecting these flies for the overarching goal of improving epidemiological knowledge on AAT in the southern area of Chad. Despite the limitation that less than $60 \%$ of the tsetse flies 
caught were identified, the capture of G. m. submorsitans, G. f. fuscipes and G. tachinoides in the south of Chad confirms the results of recent studies demonstrating the presence of these tsetse flies in this area [12,13] as well as those of much older studies carried out more than 50 years ago $[24,25]$.

The low apparent density of tsetse flies recorded in November 2018 compared to February 2019 and 2020 (dry season) could be explained by some bioclimatic conditions that vary between the trapping periods. Indeed, the month of November corresponds to the end of the rainy season, and buried pupae likely did not survive submersion resulting from the increased level of flowing water and overflow of rivers in the Chari-logone subbasin. Moreover, the number of rainy days in November is an important determinant factor of tsetse fly density as the movements of tsetse flies are limited in time and space during this period month, especially during the rainy days, thus restricting access to resting and/or emerging sites. Also, since rainy days are not favourable in terms of tsetse flies moving towards the traps, trapping during rainy days, as was conducted during the present study, is an additional factor explaining the low density of tsetse flies caught at the end of the rainy season in November.

The large number of male G. m. submoritans (68.6\%) compared to females (31.4\%) contradict previous results of a study in Nigeria where approximately equal numbers of males and females were reported for the same tsetse species [25]. One explanation for the low number of females recorded in the present study is that in harsh conditions, most flies are hidden in vegetation and restrict their movements. In such conditions, tsetse fly movements are probably extremely reduced and, interestingly, females have been reported to be active only for 5 min per day [26]. Moreover, the sampling device could introduce some bias in the number of males or females caught because the sex ratio of caught tsetse flies can greatly vary according to the type of trap [17].

The identification of G. m. submorsitans as the main cyclic vector of African trypanosomes in the area of Lake Iro is in agreement with results obtained in the Yankari Game Reserve and Lake Kainji National Park of Nigeria [25]. Known as the savannah tsetse species, the predominance of G. m. submorsitans in our study site could be explained by the bioclimatic conditions, with the wooded savannah of the area offering a favourable environment for its life-cycle. Moreover, G. m. submorsitans is largely dependent on big game for blood meals [27], and the proximity of Lake Iro to the Zakouma National Park [28, 29], which contains large populations of wild animals that move towards Lake Iro during the dry season, provide abundant animals for the blood meals. This tsetse species appears to be the most important vector of AAT in the locality of Lake Iro.

The lower number of G. f. fuscipes and G. tachinoides caught could be explained by the unfavourable bioclimatic conditions for their development. Known as riparian species due to their high preference for areas with a high soil moisture content, such as mangroves, lake shores and gallery forests along rivers, the bioclimatic conditions (type of soil, temperature, humidity) around the Lake Iro does not offer favourable environments for development of these tsetse species. Despite their low number, it is important to note that G. f. fuscipes and G. tachinoides may play a role in the epidemiology of AAT, as evidenced by the identification of several pathogenic trypanosome species in these tsetse fly species. These species could, therefore, facilitate the transmission of pathogenic trypanosome species to vertebrate hosts.

Four trypanosome species, namely $T$. simiae, $T$. congolense savannah, T. vivax and T. godfreyi, were identified in all three tsetse fly species caught in this study, indicating that each of these flies could play a role in the epidemiology of AAT in the area of Lake Iro. Although the numbers of G. f. fuscipes and G. tachinoides caught were low, the trypanosome infection rate in each tsetse species was high (56.9\% for G. m. submorsitans, $72.7 \%$ for G. f. fuscipes and $66.6 \%$ for G. tachinoides). Trypanosome infection rates obtained in the present study are higher than those reported by in earlier studies $[9,30]$. Although we did not perform any analysis of blood meals in this study, it is likely that G. m. submorsitans in the area of lake Iro tend to feed mainly on wild animals since, as mentioned above, the Zakouma National Park is located relatively close to this lake. In this context, the transmission cycle of trypanosomes in this area is predominantly "wild animal/ tsetse/wild animal". The high infection rates reported in tsetse flies indicate a high transmission of African trypanosomes between tsetse flies and wild animals; however, cattle also move in and around Lake Iro, and thus are exposed to tsetse bites and consequently to trypanosome infections. These cattle are therefore at high risk for trypanosome infections. Moreover, the detection of T. congolense savannah in the three tsetse species caught in this study testifies not only its high circulation between tsetse and mammals, but also to its potential impact on infected cattle. As such, the results of this study suggest that the numerous wild and domestic animals residing in or moving into/out of the area of Lake Iro could be potentially infected by different trypanosome species. AAT could therefore be considered as a serious risk for animal health and animal breeding in the area of Lake Iro.

Comparison of the proboscis and tsetse body in terms of trypanosome infection revealed that there were a higher number of infections in the tsetse body than in the 
proboscis, possibly due to the presence of trypanosome infections in different organs, such as the migdut and/or the salivary glands. These results are in agreement with those reported in Nigeria where the proboscises of different tsetse species were less infected than salivary glands and guts [30,31]. Nevertheless, the possibility of having remaining blood meals with trypanosome infections in tsetse midguts cannot be ruled out. As no dissection of tsetse flies was performed to determine which tsetse organ was infected by each trypanosome species, it is not possible to speculate on immature or mature infections of different trypanosomes. The trypanosome infections reported in tsetse bodies could be assimilated into immature and/or mature infections depending on the trypanosome species involved. For example, the identification of T. vivax in the proboscis testifies to a mature infection because $T$. vivax migrates directly from the midgut via the proventriculus to the proboscis where it develops into the trypomastigote and metacyclic forms [32]. The high T. vivax infection rate observed in the proboscis $(9.3 \%)$ compared to the tsetse body (2.0\%) could be explained by the fact that its developmental cycle occurs predominantly in the proboscis. The detection of $T$. vivax in the proboscis indicates a high probability of its transmission to mammals during blood meals, but its detection in the tsetse body is strange because its developmental cycle is normally restricted to the mouthparts. Nevertheless, the detection of T. vivax in the tsetse body can be explained in part by the residual blood meals taken on mammals infected by T. vivax, or by recent infections in which these parasites are in the process of migrating towards the proboscis to complete their developmental cycle. In this study, the presence of DNA from T. vivax or other trypanosome species was taken as evidence of an active infection of this trypanosome species. However, it is important to mention that DNA from dead trypanosomes can be amplified and detected in the absence of any active trypanosome infection.

Compared to the infection rate in the proboscis, the high infection rates reported in the tsetse body for $T$. simiae and T. godfreyi are in line with their developmental cycles. These results indicate not only a probable high transmission of these trypanosomes, but also the presence of suitable vertebrate hosts for these parasites. Although pigs have been reported to be suitable hosts for T. simiae, their absence in the locality of Lake Iro suggests the presence of other vertebrate hosts, such as wild boar and warthogs that have been frequently observed during entomological surveys. Trypanosoma simiae is recognized to be highly pathogenic for pigs [32, 34], but the active transmission of this species is of less epidemiological value for AAT in the study area because inhabitants and visiting farmers of Lake Iro are mostly Muslim.
In this context, pig farming is not developed and, consequently, infections due to $T$. simiae are probably of limited epidemiological importance for animals breeding in this locality. While the importance of $T$. godfreyi as a pathogen of AAT remains unclear, the results of this study indicate an active transmission of this parasite in the area of Lake Iro.

The detection of $T$. congolense savanah both in the tsetse body and the proboscis indicates immature and mature infections of this trypanosome. The high infection rate of $T$. congolense savanah in tsetse bodies (11.3\%) compared to proboscises $(4.2 \%)$ is in agreement with results reported in other tsetse species [9, 31]. Taken together, these results indicate the predominance of immature infections of T. congolense in tsetse flies in the locality of Lake Iro. These immature infections could be explained by the need for T. congolense savannah, following a blood meal on infected mammals, to first establish in the midgut as the procyclic form before continuing its development and migration to the proboscis in the mature form ready to be transmitted to uninfected mammals. However, the bottleneck that has been observed in the life-cycle of trypanosomes from their establishment in the midgut to their maturation in the salivary glands or the proboscis depends on the trypanosome species, possibly also explaining the low infection rate of trypanosomes in the proboscis compared to the tsetse body. Taken into consideration the virulence of $T$. congolense savanah and T. vivax and their real impact on animal health $[35,36]$, the detection of these trypanosomes in $G$. f. fuscipes, G. tachinoides and G. m. submorsitans shows that cattle in the locality of Lake Iro and those passing through there during transhumance are potentially at higher risk for AAT. The high infection rates reported in the proboscis indicate mature infections of $T$. vivax and $T$. congolense savanah, demonstrating that each tsetse fly carrying such infections will easily transmit trypanosomes to healthy mammals during each blood meal. Investigations on tsetse distribution and trypanosome infections in livestock living in and around the area of lake Iro are becoming important for the understanding of the current epidemiological situation of AAT, and also for the designing and implementing disease control operations. While waiting for political and financial commitments at the national level, and also for additional entomological data as well as data on trypanosome infections in livestock, some control measures can be initiated in some risky biotopes by setting up traps and/or screens or by spraying insecticides to kill tsetse flies to prevent trypanosome infections, especially in livestock that pass through this area. Furthermore, regular treatment of infected livestock with trypanocides could be planned to reduce the number of infected animals and, consequently, 
the probability of tsetse flies feeding on such animals and faciliate trypanosome transmission.

Our results showing no significant difference in the trypanosome infection rates according to sex are in agreement with experimental infections [38, 39]. However, in natural tsetse populations, several studies have reported female flies to be more infected than their male counterparts because females live longer [31, 40]. As already mentioned above, the high temperature recorded in the area of Lake Iro probably induced a high mortality rate among females, thus explaining the similar trypanosome infection rates observed in male and female flies.

Although no information on mixed infections involving mature infections of different trypanosome species can be inferred, the detection of both $T$. vivax and $T$. congolense savanah in the proboscis of one tsetse fly indicates the possibility of these two highly pathogenic trypanosomes being transmitted to one animal during a single blood meal. If such a transmission occurs, could each of these trypanosome species have the potential to develop in the vertebrate host? Some mixed infections detected in tsetse flies could result from a single blood meal on mammals infected by different trypanosome species. It has been demonstrated that among infected tsetse flies, a mature infection will develop in only a proportion of those harbouring immature trypanosome infections [31, 41]. All trypanosome species detected in tsetse flies harboring mixed infections were unable to develop to the mature form and, consequently, could not be transmitted to mammals. The high number of tsetse flies with double infections, namely $T$. congolense savannah and T. simiae, or T. congolense and T. godfreyi, suggests not only high circulation of these trypanosome species but also their predominance in mammals.

\section{Conclusion}

The results of this study reveal the presence of G. m. submorsitans, G. f. fuscipes and G. tachinoides in the area of Lake Iro in the south of Chad. Glossina m. submorsitans appeared to be the main vector of African trypanosomes in this area. Several pathogenic trypanosomes, including T. vivax, T. simiae, T. godfreyi and T. congolense savanah can be transmitted by different tsetse species. These findings highlight the risk of AAT for livestock breeding and the importance of assessing trypanosome infections in livestock in the area of Lake Iro.

\section{Abbreviations}

AAT: Animal African trypanosomiasis; ADT: Apparent density of tsetse flies per trapping; COl: Cytochrome c oxidase 1 gene; HAT: Human African trypanosomiasis; ITS1: Internal transcribed spacer 1.

\section{Acknowledgements}

We sincerely thank the Deutsche Forschungsgemeinschaft (DFG) for the financial support necessary for the realization of this project. Our thanks also go to the staff of the Laboratory for Biomolecular Interaction Bremen, the University of Bremen, Germany for their technical assistance and fruitful practical discussions during the laboratory work. We also thank the regional representation of the Ministry of Livestock of Moyen Chari in Chad, the military and traditional authorities for their guidance and support during sample collection.

\section{Authors' contributions}

GS, DS, VKP, SK and HMH contributed to the design of the Project. DS, IMAM, SK and PB contributed in sample collection and laboratory analysis. DS and GS analyzed the data. DS and GS and HMH wrote the Manuscript. All authors read and approved the final manuscript.

\section{Funding}

This study was financed by Deutsche Forschungsgemeinschaft (DFG Ke428/13-1) through the Project entitled "Animal African Trypanosomiasis in Humans, An emergency zoonosis?".

\section{Availability of data and materials}

All data generated and/or analyzed during this study are included in this article.

\section{Declarations}

Ethics approval and consent to participate

Not applicable.

\section{Consent for publication}

Not applicable.

\section{Competing interests}

The authors declare that they have no competing interests.

\section{Author details}

${ }^{1}$ Molecular Parasitology and Applied Entomology Unit, Department of Biochemistry, Faculty of Science, University of Dschang, PO Box 67, Dschang, Cameroon. ${ }^{2}$ Centre for Biomolecular Interaction Bremen, Department of Biology and Chemistry, University of Bremen, Bremen, Germany. ${ }^{3}$ Laboratory of Biology and Ecology (LABEA), Department of Animal Biology, Faculty of Science, University of Dschang, PO Box 067, Dschang, Cameroon. ${ }^{4}$ Institut de Recherche en Elevage Pour Le Développement, BP 433, Rue Farcha, N'Djamena, Chad.

Received: 24 February 2021 Accepted: 11 May 2021

Published online: 02 June 2021

References

1. Büscher P, Cecchi G, Jamonneau V, Priotto G. Human African trypanosomiasis. Lancet. 2017:390:2397-409.

2. Geiger A, Ponton F, Simo G. Adult blood-feeding tsetse flies, trypanosomes, microbiota and fluctuating environment in sub-Saharan Africa. ISME J. 2015;9:1496-507.

3. Cecchi G, Mattioli RC, Slingenbergh J, De la Rocque S. Land and tsetse distribution in sub-Saharian Africa. Med Vet Entomol. 2008;4(8):12-43.

4. Angara TTE, Ismail AA, Ibrahim AM. An overview of the economic impact of animal trypanosomiasis. GJRA. 2014;3:2277-8160.

5. Shaw PM. Economics of African trypanosomiasis. In: Maudlin I, Holmes $\mathrm{PH}$, Mile MA, editors. The trypanosomiases. CABI Publishing: Wallingford; 2014. p. 369-402.

6. Schofiel SJ, Kaboyo JP. Trypanosomiasis vector control in Africa and Latin America. Parasites Vectors. 2008;1(1):24.

7. Diall O, Cecchi G, Wanda G, Argilés-Herrero R, Vreysen MJB, Cattoli G, et al Developing a progressive control pathway for African animal Trypanosomosis. Trends Parasitol. 2017;33(7):499-509. 
8. Mamoudou A, Njanloga A, HayatouA, Suh PF, Achukwui MD. Animal trypanosomiasis in clinical implications healphy cattle of North Cameroon: Epidemiological implication. Parasites Vectors. 2016; 9:206.

9. Ngomtcho SCH, Weber JS, Ngo Bum E, Gbem TT, Kelm S, Achukwi AD. Molecular screening of tsetse flies reveals different trpanosoma species including T grayi and T. theileri in Northern Cameroon. Parasites Vectors. 2017;10:631.

10. Kamdem NC, Zebaze TAA, Estelle Mezajou ME, Amih Ofon E, Djoumessi GEB, Simo G. Identification of different trypanosome species in tsetse flies caught in the wildlife reserve of Santchou in the western region of Cameroon. Parasitol Res. 2020;119:805.

11. Ministère de l'élevage et des productions animales et l'Organisation des Nations Unies pour l'Alimentation et l'Agriculture. Recensement générale de l'élevage au Tchad. Effectifs du cheptel tchadien: principaux résultats définitifs. 2018. http://www.fao.org/tchad/actualites/detail-events/ru/c/ 1128777/ Accessed 27 Apr 2021

12. Hassane Mahamat $H$. Enquête épidémiologique et entomologique de la trypanosomiase et son vecteur dans le bassin du Mandoul. N'Djamena: Laboratoire de Recherche Vétérinaire et Zootechnique. 2003.

13. Mallaye P, Tongue LK, Ndeledje N, Hassane MH. Transmission concomitante des trypanosomes humaine et animale: le foyer de Mandoul au Tchad. Rev Elev Med Vet Pays Trop. 2014;67(1):5-12.

14. Paigbc. Plan d'aménagement intégré à base communautaire, site de Boum Kebir. Ministère de l'Environnement et des Ressources Halieutiques, Direction des Pêches et de l'Aquaculture: IRD Edition. 2012

15. Boyer JD, Rouche CN, Cres A, Servat E, Paturel J, Mahé G. SIEREM: an environnmental information system for water resources. In: 5th World FRIEND Conference. La Havana. 2006. p. 19-25.

16. Raimond C, Florence Sylvestre, Zakinet D et Abderamane M. Tchad des lacs: les zones humides sahéliennes au défi du changement global. IRD Éditions. 2019. https://doi.org/10.4000.books.irdeditions.30450.

17. Laveissiere C. Amélioration du rendement du piège biconique pour glossines (Diptera, Glossinidae) par l'emploi d'un cône inférieur bleu. Entomol Med Parasitol. 1973;3:283-6.

18. Dyer NA, Lawton SP, Ravel S, Choi KS, Lehane MJ, Robinson AS, et al. Molecular phylogenetics of tsetse flies (Diptera: Glossinidae) based on mitochondrial (COI, 16S, ND2) and nuclear ribosomal DNA sequences, with an emphasis on the palpalis group. Mol Phylogenet Evol. 2008;49:227-39

19. Adams ER, Hamilton PB. New molecular tools for the identification of trypanosome species. Future Microbiol. 2008;3:167-76.

20. R Core Team. R: A language and environment for statistical computing. Vienna: R Foundation for Statistical Computing. 2010. http://www.R-proje ct.org/.

21. Vourchakbé J, Tiofact AAZ, Kante ST, Mpoame M, Simo G. Molecular identification of Trypanosoma brucei gambiense in natural infected pigs, dogs and small ruminants confirms domestic animals as potential reservoirs for sleeping sickness in Chad. Parasite. 2020;27(63):12

22. Vourchakbé J, Tiofact AAZ, Mpoame Mbida G, Simo. Trypanosome infections in naturally infected horses and donkey of three active sleeping sickness foci in Chad. Parasites Vectors. 2020;2020(13):323.

23. Gruvel J. Tse-tse flies as vectors of trypanosomiasis in Chad. Rev Elev Med Vet Pays Trop. 1966;19:169-212.

24. Cuisance D. Réactualisation de la situation des tsé-tsé et des trypanosomoses animales au Tchad. Phase II/Zone du Lac, Guera, Salamat. Enquête réalisée du 22 mars au 20 avril 1996. CIRAD-EMVT; 1996. https://agritrop. cirad.fr/327260/. Accessed 4 Mar 2021.

25. Shaida SS, Weber SJ, Gbem T, Ngomtcho SCH, Musa UB, Achukwi MD, et al. Diversity and phylogenetic relationships of Glossina populations in Nigeria and the Cameroonian border region. BMC Microbiol. 2018. 18(1):1804.

26. Pagabeleguem S, Ravel S, Dicko AH, Vreysen MJB, Parker A, Takac P, et al. Influence of temperature and relative humidity on survival and fecundity of three tsetse strains. Parasites Vectors. 2016;9:520.

27. Reid R, Kruska RL, Deitchmann U, Thotthon PK, Leak SGA. Human population growth and the extinction of the tsetse fly. Agric Ecosyst Environ. 2000;77:227-36.

28. Dejace P, Laure Gautsr ER, Philippe Bouché. Les populations de grands mammifères et d'autruches du Parc National de Zakouma au Tchad statut et tendance d'evolution. Rev Ecol. 2000;5(55):111-34.

29. Potgieter D, Dogringar, S, Djimet, B, Lamoureaux, S. Dry season aerial total count. Zakouma National Park. Chad. Unpublished report. New York: Wildlife Conservation Society; 2011.

30. Weber JS, Ngomtcho SCH, Shaida SS, Chechet GD, Gbem TT, Nok JA, et al. Genetic diversity of trypanosome species in tsetse flies (Glossina spp.) in Nigeria. Parasites Vectors. 2019;12:481

31. Isaac C, Ciosi M, Hamilton A, Scullion KM, Dede P, Igbinosa IB, et al. Molecular identification of different trypanosome species and subspecies in tsetse flies of northern Nigeria. Parasites Vectors. 2016;9:301.

32. Ooi C-P, Schuster S, Cren-Travaillé C, Bertiaux E, Cosson A, Goyard S, et al. The cyclical development of Trypanosoma vivax in the tsetse fly involves an asymmetric division. Front Cell Infect Microbiol. 2016;6:115. https:// doi.org/10.3389/fcimb.2016.00115.

33. Penchenier L, Bodo JM, Bureau PH, Morlais I, Djoha S, Herder S. Utilisation de la PCR sur sang pour le diagnostic des trypanosomiases porcines. Bull Liaison Doc OCEAC. 1996;29:50-3.

34. Simo G, Aonganyi T, Nkinin SW, Njiokou F, Herder S. High prevalence of Trypanosoma brucei gambiense groupe 1 in the pigs from Fontem sleeping sickness focus in Cameroon. Vet Parasitol. 2006;139:57-66.

35. Swallow BM. Impact of trypanosomiasis on African agriculture. PAAT Technical and Scientific Series. Rome: FAO; 2000.http://www.fao.org/3/ X4755EN/x4755en.pdf. Accessed 27 Apr 2021.

36. Trail JMC, D'letem GDM, Feron A, Kankiese O, Mulungo M, Pelo M. Effect of trypanosomes infection, control of parasitaemia and control of anaemia development on productivity of N'dama cattle. Acta Trop. 2000;48:37-45.

37. Moloo SK, Sabwa CL, Kabata JM. Vector competence of Glossina pallidipes and G. morsitans cetralis for Trypanosoma vivax, T. congolense, and T. b. brucei. Acta Trop. 1992;51(3-4):271-80

38. Welburn SC, Maudlin I. The nature of the teneral state in Glossina and its role in the acquisition of trypanosome infection in tsetse. Ann Trop Med Parasitol. 1992;86(5):529-36.

39. Desta M, Menkir S, Kebede A. The study on tsetse fly (Glossina species) and their role in trypanosome infection rate in Birbir valley, Baro Akobo River system, western Ethiopia. J Vet Med Anim Health. 2013;5(7):186-94.

40. Jamonneau V, Ravel S, Koffi M, Kaba D, Zeze DG, Ndri L, et al. Mixed infections of trypanosomes in tsetse and pigs and their epidemiological significance in a sleeping sickness focus of Côte d'Ivoire. Parasitology. 2004;129:693-702.

41. Kubi C, Van Abbelle J, Dorny P, Coosemans M, Marcotty T, Andp T, et al. Ability of trypanosome-infected tsetse flies (Diptera: Glossinidae) to acquire an infection with a second trypanosome species. J Med Entomol. 2005;42(6):1035-8.

\section{Publisher's Note}

Springer Nature remains neutral with regard to jurisdictional claims in published maps and institutional affiliations. 